\title{
DAS POLÍTICAS CONTRADITÓRIAS DE FLEXIBILIZAÇÃO E DE CENTRALIZAÇÃO: REFLEXÕES SOBRE A HISTÓRIA E AS POLÍTICAS DA EDUCAÇÃo INFANTIL EM GoiÁs*
}

Ivone Garcia Barbosa**

\section{RESUMO}

$\mathrm{O}$ artigo apresenta um conjunto de reflexões teórico-metodológicas sobre a educação infantil no estado de Goiás, destacando um conjunto de informações e dados significativos no estado e, em especial, no município de Goiânia. Os dados apresentados, constituídos a partir de uma perspectiva dialética (Marx, 1983), tiveram como referência vários estudos e investigações desenvolvidos nos últimos sete anos. Várias produções marcaram a trajetória do Grupo de Estudos e Pesquisas sobre a Infância e sua Educação, da FE/UFG (Gepied), articulando-se ao projeto de pesquisa "Políticas públicas e educação da infância em Goiás: história, concepções, projetos e práticas". Os resultados das investigações e reflexões permitem discutir a constituição do campo específico da educação infantil e das políticas a ela relacionadas no estado e em níveis nacional e internacional, traduzindo-se suas diversas contradições. Observa-se que a reestruturação produtiva, o fortalecimento do neoliberalismo e as políticas de descentralização de recursos e centralização de poder no estado gera um paradoxo: a educação infantil é vista como forma de efetivação de uma política voltada para o desenvolvimento político-social, mas, ao mesmo tempo, é classificada como problema, havendo um movimento crescente de privatização e filantropização do público no caso da educação infantil.

Palavras-chave: Educação infantil. Neoliberalismo. Políticas públicas.

* Artigo recebido em 24/12/2007 e aprovado em 12/05/2008.

** Professora da Universidade Federal de Goiás. E-mail: garciasoares@cultura.com.br 


\section{INTRODUÇÃO}

Este artigo apresenta um conjunto de reflexões teórico-metodológicas realizadas pelo Grupo de Estudos e Pesquisas sobre a Infância e sua Educação da FE/UFG ao longo dos últimos sete anos. Desenvolvemos, de modo articulado, várias investigações delimitadas em formato de subprojetos, os quais vinculam-se ao projeto de pesquisa "Políticas públicas e educação da infância em Goiás: história, concepções, projetos e práticas", coordenado pela professora Ivone Garcia Barbosa, da Faculdade de Educação da UFG.

Os dados da pesquisa indicam que discutir a constituição de políticas para a educação infantil é, sem dúvida, uma tarefa complexa, sobretudo quando analisamos os fatos e processos históricos de uma perspectiva dialética (MARX, 1983), que exige uma compreensão da realidade em movimento através de um olhar atento e crítico aos seus multideterminantes. Nesse caso, buscamos apreender vários elementos históricos constitutivos da configuração das políticas educacionais que, no caso da educação infantil, articula-se diretamente às políticas sociais mais amplas.

Diversos autores (GENTILI, 1998; Tommasi; WARDE; HADDAD, 2000) têm estabelecido a relação entre o conjunto de revisões que foram impostas ao sistema produtivo capitalista e a concepção de educação como prática de preparo do trabalhador para atuar segundo a lógica do mercado. Tal processo, pelo que podemos perceber, demandou novas teorias de aprendizagem e novos conteúdos e habilidades a serem reforçados e/ou aprendidos desde a infância, tornando esta etapa um dos pontos nodais a serem debatidos no bojo das propostas de políticas sociais públicas, no âmbito da educação, da saúde e da assistência. Desse prisma, a educação da infância de baixa renda é apresentada como vital para o controle da convulsão social decorrente do agravamento das crises econômicas, da pobreza e da miséria da maioria da população do planeta.

As proposições políticas resultantes desse movimento vêm sendo caracterizadas como de natureza neoliberal, havendo uma nítida retração das obrigações e do papel do Estado. Este outorga o dever de garantir a oferta e de manter os diferentes projetos de educação à chamada "comunidade", termo que não representa certamente todo o jogo de forças existentes nos diferentes grupos e suas interrelações.

À minimização dos deveres de provedor de recursos do Estado acrescenta-se uma paulatina centralização da avaliação e do controle de 
certas linhas de implementação de políticas que devem ser garantidas por estados e municípios. Tais medidas no Brasil, ainda que se desenhem de modo diversificado, levaram às políticas educacionais de descentralização, ocorrendo uma redefinição das funções do Estado e a privatização das relações sociais no interior do sistema público de ensino. Essas transformações incentivaram e permanecem incentivando muitas "parcerias", nas quais, segundo alguns dos nossos dados de pesquisa no estado de Goiás, o interesse público nem sempre prevalece. Ademais, observa-se a criação de novos papéis para os diferentes atores educativos e novos valores de socialização, respaldados por distribuições de competências entre o Estado e a sociedade e em relações fundadas em práticas mercadológicas que implicam atitudes competitivas, individualistas e privatistas. A esse movimento acrescenta-se a fetichização da necessidade de um conhecimento instrumental - tanto para a infância como para os seus professores -, promovendo o consumo de idéias e projetos internacionais por países como o Brasil, consumo esse incentivado por organizações multilaterais, entre eles o Banco Mundial e a Unesco.

Tendo por referência essa discussão, buscamos, no presente artigo, refletir de modo sistemático e crítico sobre o processo histórico de constituição e de desenvolvimento de políticas públicas em Goiás, assinalando alguns dados relevantes que resultam de pesquisas - histórica, bibliográfica, documental e empírica - desenvolvidas desde o ano de 1999 e que cotejam vários aspectos das políticas e práticas no campo da educação da infância. Apresentamos inicialmente alguns marcos significativos na política estadual, enfatizando, igualmente, aspectos relevantes da década de 1990 em Goiânia, quando se tornam expressivas as ações político-ideológicas que materializam um projeto de educação para a infância menor de sete anos, caracterizado por paradoxos na sua concepção e operacionalização.

\section{Políticas PÚBliCAS PARA A INFÂNCIA EM GOIÁS: MARCOS A PARTIR DA DÉCADA DE 1950}

Resgatar a historicidade das instituições e dos contextos educativos significa, antes de tudo, compreendê-las em suas várias dimensões - social, cultural, ideológica, político-econômica -, em suas relações interindividuais e coletivas, em suas concepções sobre os processos biopsicossociais do desenvolvimento infantil. Além disso, a historicidade constitui 
um aspecto e, ao mesmo tempo, uma categoria teórica necessária para a desnaturalização dos conceitos de infância e educação, bem como para a compreensão das políticas atuais em educação infantil, cujas origens foram delineadas e implementadas ao longo da história brasileira.

Apreender esse dinamismo e essa dialeticidade característicos da realidade é fundamental para compreendermos a estruturação de um campo específico da educação da infância. Conforme dados de pesquisa e inspirados na categoria da totalidade, dialeticamente articulada aos processos de singularização dos fenômenos, podemos dizer que a situação de atendimento a crianças em Goiás ocorreu nos moldes dos outros estados brasileiros. Documentos da Fundação da Criança, do Adolescente e da Integração do Deficiente (Funcad-GO), permite-nos perceber, apesar dos discursos oficiais daqueles que assumiram o controle do Estado, que as políticas social-assistencial e educacional não foram prioridades nos planejamentos governamentais. Esse fato expressou-se no montante dos recursos financeiros alocados para custeio e investimento naquelas áreas, desenvolvendo-se dentro de uma perspectiva restrita através de uma prática dirigida a grupos minoritários. Não foi por iniciativa estatal que surgiram as primeiras creches em Goiânia, por exemplo, mas sim devido a iniciativas filantrópicas ligadas às instituições de caridade, tendo sido criadas as creches "Anália Franco" (1958) e "Obra do Berço" da Irradiação Espírita Cristã (1967). No âmago dessas propostas se expressa e constitui-se uma concepção de creche como instituição predominantemente de tarefa moralizadora, atrelada à idéia de prestação de favor, de doação, distanciando-se da esfera dos direitos, favorecendo posturas descompromissadas quanto à alocação de recursos oficiais, situando as propostas de educação para crianças pequenas em um caráter emergencial e paliativo (CAmpos, 1985; Rosemberg, 1989; BARBosa, 1999). Esta tendência, como mostram Barbosa (1997, 2001, 2005); Alves (2002); Moraes (2003); Arantes (2003); Aguiar (2004); Vieira (2004); Soares (2005); Márquez (2006), entre outros, ainda persiste no cenário do Estado, refletindo as políticas nacionais e internacionais.

É importante, por outro lado, do ponto de vista das contradições, considerar o avanço dos movimentos sociais que exigiram e conduziram a uma permanente busca de resolução dos conflitos sociais por parte dos governos em níveis federal, estadual e municipal. Nesse jogo de forças e interesses antagônicos, observa-se que, em geral, a negociação se deu e ainda se dá através de políticas de consenso. Nesse caso, mesmo sem 
expressar real interesse transformador na discussão histórica sobre a educação infantil, tais políticas favoreceram nos anos 70 e 80 a expansão da educação infantil, quando surgem as primeiras creches públicas em Goiânia - "Creche Tio Romão" e "Centro Infantil Tio Oscar". Na década de 1980, outras ações governamentais, como a inauguração da "Casa da Criança" e do "Projeto Creche" (1984), pela Fundação das Legionárias do Bem-Estar Social, buscaram viabilizar a operacionalização de atividades com crianças na faixa etária de três a cinco anos, de famílias de média e baixa renda. O Estado manteve uma política de expansão dos atendimentos e de contratação de profissionais, especialistas em diferentes campos, contando com "ajuda diversa" de creches particulares de caráter filantrópico. Um seminário de 1987, cuja temática foi a educação infantil apontou para uma concepção única de trabalho com creches, definidas como equipamento social auxiliar da família destinado ao atendimento de crianças de zero a seis anos em regime de semiinternato, com doze horas diárias, funcionando o ano todo.

Naquele mesmo ano, criou-se a Comissão Estadual de Creches representada por técnicos dos diversos órgãos públicos envolvidos e pela Associação de Creches. Foram extintos vários órgãos estaduais, passando-se o controle para a Fundação da Promoção Social (1987), que ampliou o número de creches e criou, em bairros periféricos, vinte e um Núcleos de Apoio à Comunidade (NACs), em 1988. Estes constituíram creches, centros comunitários e posto policial. Diante da demanda por vagas, a fundação resolveu alterar a programação das creches dos centros comunitários, instalando creches alternativas, com um período de seis horas de atendimento.

Este dado histórico é importante de ser destacado, posto que tais políticas nunca se isentaram das influências de recomendações nacionais e, sobretudo, internacionais. Levantamentos sobre as influências dos organismos multilaterais e suas concepções de infância, cultura e educação infantil (RoSEMBERG, 2002; MARQUEZ, 2006) mostram que uma das recomendações existentes nos documentos daqueles organismos é a de recondução e redução dos recursos a serem aplicados na educação de crianças pequenas, principalmente na educação de crianças de até três anos - atendidas em creches -, sendo aceitável e até aconselhável essa mudança na quantidade de horas de atendimento. Essa atitude coaduna-se com o incentivo da educação em instituições pré-escolares, que possibilitam aproveitar espaços já institucionalizados, permitindo aplicar as 
verbas em consonância com o ensino fundamental, o que demarca uma das defesas do ensino de nove anos, defesa retomada nos anos $2000 \mathrm{em}$ nível nacional.

Dessa movimentação em torno da temática resultaram ações locais e nacionais que excluíram do planejamento as demandas da educação de crianças menores de sete anos. De acordo com os nossos dados de pesquisa, os anos 90 marcam no campo das políticas estaduais em Goiás uma ênfase em programas que não se destinam ao atendimento da infância pequena e às creches. As ações governamentais voltam-se para projetos alternativos como, por exemplo, Meninos e Meninas de Rua, promovendo um enxugamento na máquina administrativa, demitindo funcionários em cargos diversos, diminuindo o já reduzido número de funcionários nas creches, ocorrendo o fechamento de unidades. O fortalecimento de uma política de Estado mínimo aumenta o déficit de pessoal nas instituições, incentivando o trabalho voluntário e a contratação de mão-de-obra de adolescentes de quatorze a dezessete anos no trabalho de faxina e de lavanderia, propondo um Programa de Trabalho Educativo Remunerado (Proter). Essa política passou a ser coordenada, desde 1995, pela Fundação da Criança, do Adolescente e da Integração do Deficiente (Funcad-GO), a qual assumiu a gerência do trabalho das creches.

A partir de 1999, com a posse de um novo governo no estado, as unidades educativas contaram com um número reduzido de funcionários, havendo a suspensão de verbas para a educação infantil, prejudicando ainda mais a qualidade do atendimento às crianças, acarretando redução do número de vagas ofertadas, apesar do aumento da demanda. É esse clima de mudanças e retrocessos que demarca o campo da educação infantil, considerada, desde a Lei de Diretrizes e Bases da Educação Nacional, de 1996, como a primeira etapa da educação básica - no plano estadual, ocorre parte da transferência das creches para o âmbito municipal, processo esse marcado por disputas políticas e por variados conflitos conceituais.

\section{EducaÇão Infantil na Rede Municipal de Ensino: ImPasses E POTENCIALIDADES EM GOIÂNIA}

Inúmeros impasses e movimentos marcam as disputas conceituais e políticas em torno da educação infantil nos municípios goianos. Para efeito de análise no presente artigo, resgatamos algumas análises já ela- 
boradas quanto às informações sobre Goiânia, capital do estado. Nela, assim como em vários municípios, o atendimento às crianças de zero a seis anos foi organizado através da iniciativa privada, filantrópica e de instituições públicas municipais e estaduais criadas e mantidas por órgãos de assistência social, aos quais se mantiveram vinculadas até a sua inserção no sistema municipal de ensino, conforme determina a LDB (Lei n. 9.394/96). Importante destacar que nem todos os municípios constituíram rede própria e que o governo estadual, através da Secretaria da Educação e Assistência social, além de ONGs, permanecem responsáveis pelos trabalhos das instituições nesses casos. Ressalta-se ainda que muitas iniciativas - em Goiânia, Jataí, Rio Verde, entre outros - contaram com a presença de grupos femininos, compondo associações sociais, religiosas e filantrópicas, na elaboração de projetos e na criação de instituições de atendimento à criança "carente", resultando no processo o estabelecimento de "parcerias" entre as instituições filantrópicas, públicas e grupos privados, dispostos a investir de algum modo nas propostas.

$\mathrm{O}$ atendimento às crianças menores de sete anos por parte da Secretaria Municipal de Educação (SME), em Goiânia, iniciou-se em 1985, com a inserção de crianças de seis anos de idade no ensino fundamental, por meio do projeto Bloco Único de Alfabetização, desenvolvido até 1997. No período de 1993/1994, constituiu-se um Grupo de Políticas Educacionais que estudou a questão do atendimento a crianças menores de seis anos, resultando nas primeiras medidas de inserção da educação infantil na esfera das políticas públicas municipais, dentre as quais a celebração de convênios com instituições filantrópicas; ${ }^{1}$ a lotação de professoras nas creches da Fumdec; a elaboração de um plano que captou recursos do Fnde e do tesouro municipal. Tais recursos foram destinados à preparação da infraestrutura física, aquisição de equipamentos e mobiliários específicos para absorver a demanda de pré-escolas atendidas pelas unidades da Fumdec. Em 1995, realizou-se um curso de capacitação específica para os professores que assumiriam 23 turmas de pré-escolas implantadas em escolas de ensino fundamental, visando atender crianças a partir de quatro anos e nove meses. Estruturou-se, daí, a primeira "Proposta pedagógica para a pré-escola", único documento oficial da secretaria (aprovado e homologado), disponível aos professores até o ano de 2004, sendo que sua abordagem remete a uma versão escolarizadora e disciplinar do conhecimento a ser desenvolvido no trabalho docente. 
Em 1998, a SME iniciou a preparação para a absorção das 13 unidades de educação infantil sob a responsabilidade da Fumdec. Foi estruturada a Divisão de Educação Infantil (DEI), no Departamento de Ensino, iniciando um conjunto de estudos e discussões, sob assessoria da Faculdade de Educação da Universidade Federal de Goiás. Elaborouse uma proposta de "Política de atendimento para a educação infantil" - escrita em 1999, mas que não foi homologada - e realizou-se a formação e qualificação da equipe responsável por ações de formação dos professores, de acompanhamento e articulação da educação infantil na rede municipal de ensino. A equipe que compôs a divisão era formada de professores da rede municipal que se empenharam para atender às creches, chamadas então de Centros Municipais de Educação Infantil (Cmeis), advindos da Fundação de Desenvolvimento Comunitário (Fumdec), assim como os Centros de Educação Infantil (CEIs), conveniados com a Secretaria de Educação.

A formação continuada para os profissionais que atuavam naquelas instituições foi elaborada, coordenada e executada pela DEI (1998/1999). Em 2000, as ações de formação foram assumidas por outra equipe, pertencente ao Centro de Formação de Profissionais da Educação (Cefpe), criado no ano anterior. A DEI também elaborou documentos para nortear a implementação de uma política e de um currículo de educação infantil, formulando-se as "Diretrizes norteadoras para o currículo da educação infantil", documento aprovado pelo Conselho Municipal de Educação (Resolução CME n. 1/2001), mas que não foi homologada pela nova gestão que assumiu a pasta em 2001. Neste mesmo ano, as ações da SME direcionaram-se para uma avaliação, visando à reelaboração de toda a proposta político-pedagógica da SME para a gestão 2001-2004. Houve substituição de toda a equipe da DEI e outras ações também foram interrompidas, além da proposta de currículo, inclusive a formação continuada. A SME propôs a assumir, entretanto, a melhoria do espaço físico, sendo realizadas algumas ações para a superação das deficiências.

No contexto regional, importa destacar a aprovação da LDB do Sistema Educativo de Goiás, Lei Complementar n. 26, de 28 de dezembro de 1998, cuja elaboração, em um processo amplamente participativo, representou uma conquista no exercício democrático na política governamental Ademais, as pequenas modificações relativas à educação infantil que foram introduzidas representaram avanços para a área: por exemplo, na determinação de que a educação infantil seja assegurada, 
preferencialmente, em estabelecimentos públicos, e não apenas oferecida como o previsto na LDB Nacional/96; a inclusão do aspecto ético do desenvolvimento da criança e da promoção da ampliação das experiências infantis como objetivos da educação infantil; a especificação de elementos sobre os projetos pedagógicos e curriculares da educação infantil; a consideração dos níveis de conhecimento e não somente de faixas etárias na organização das turmas (BARBOSA; NogUeIRA, 2001).

No ano de 1999, efetivou-se a transferência da educação infantil da Fumdec para a SME (treze unidades e sessenta e quatro convênios de cooperação técnico-financeira), expandindo o atendimento na rede municipal, ao mesmo tempo em que, progressivamente, ampliava-se o acesso às turmas de pré-escola para as crianças de cinco anos. O conselho municipal de educação (CME), estabelecido em 1998, fixou as primeiras normas para a educação infantil no sistema municipal de ensino, através da Resolução-CME n. 014/99, substituída pela Resolução n. 088, de 20 de agosto de 2003. Regulamentou vários aspectos da organização e do funcionamento das instituições de educação infantil, estabelecendo critérios e procedimentos para o cadastramento e a autorização de funcionamento de todas elas, públicas e privadas. Além de referenciar-se no Estatuto da Criança e do Adolescente (ECA), de 1990, e na LDB/96, o conselho passou a sintonizar-se com as diversas orientações contidas no Plano Municipal de Educação (PME), aprovado em junho de 2004, propondo-se a contribuir para a superação do assistencialismo e do dualismo cuidar-educar, afirmando a cidadania da criança.

Essa postura do conselho municipal de educação, no entanto, não representa a única posição quanto aos possíveis arranjos educativos e às concepções de infância e criança. Ao analisarmos as informações dos diversos documentos e trabalhos de pesquisa que tratam da temática educação infantil no município, verificamos que o atendimento às crianças de zero a seis anos coordenado pela SME foi, historicamente, adquirindo características peculiares. Coexistiram, nesse processo, diferentes instituições com diversos vínculos e uma multiplicidade de modos de organização e de funcionamento (BARBOSA, 1999; BARBOSA, Alves, Martins, 2005).

Percebe-se, ainda, a simultaneidade de diferentes formas de funcionamento, especialmente no tocante à pré-escola, que na SME foi sendo atendida em: a) turmas de Ciclo I, para as crianças de 6 anos, incorporadas ao ensino fundamental, portanto em outro nível de ensino; b) 
turmas de pré-escola, para crianças de cinco anos, em escolas de ensino fundamental que funcionam meio-período; c) agrupamentos para crianças dos quatro aos seis anos, em Ceis e Cemeis, em período integral. A partir de 2002, esse atendimento foi limitado às crianças de cinco anos. Já o atendimento em creche, destinado na LDB às crianças de zero a três anos de idade, continuou sendo oferecido majoritariamente em Ceis e Cmeis, que funcionam em período integral e, em sua maioria, recebem crianças a partir do nascimento até cinco anos e onze meses. Ressalta-se que, até o ano 2001, o atendimento atingia também as crianças de seis anos. Em 2004, observa-se a incorporação de parte das crianças de seis anos no ensino fundamental, elevando a taxa de escolarização dessas crianças, fato a ser debatido considerando-se as repercussões no currículo e na organização da escola e, sobretudo, a garantia dos direitos da criança a uma educação menos tradicional e escolarizante/preparatória, tal qual temos criticado na história da educação infantil (BARBOSA, 2001). Aos poucos, o atendimento parece tender a ganhar uma diferenciação explícita quanto à creche e à pré-escola, dicotomizando não apenas o locus de atendimento, mas também o projeto pedagógico e a proposta de formação dos profissionais que neles atuam.

Quanto à organização da rede municipal de ensino, os dados estatísticos referentes ao ano de 2002 (Censo Escolar Inep/MEC, 2002) indicavam um significativo aumento no número de crianças atendidas no município, fato que se deve em parte ao processo de municipalização das creches do estado. Importante destacar que, ao analisarmos o quantitativo de crianças atendidas em instituições infantis privadas com convênio parcial com o município no ano de 2003, verificamos que, embora o número de Cmeis e de crianças atendidas nesses espaços públicos tenha aumentado entre os anos de 1999 e 2003, houve uma maior concentração de atendimento no setor privado.

Nossas análises indicaram que no período de 1995 a 2003 houve uma tendência em estabelecer convênios/parcerias entre a SME e instituições privadas. Essa prática, antiga no processo de constituição do campo de atendimento da infância no Brasil, é assumida, por exemplo, no regimento dos Cmeis da rede municipal de educação de Goiânia/2004. Neste aparece indicado que projetos dos centros não serão necessariamente assegurados com o apoio dos recursos do próprio município, posto que os orçamentos anuais, votados nos órgãos competentes, não preveem verba específica para ser alocada na educação infantil, apesar de 
a LDB deixar clara a responsabilidade de cada município para essa etapa educacional. Delega-se, no entanto, às próprias instituições o "direito" e o "dever" de buscar a autonomia/auto-sustentação de seus projetos, delineando-se uma das modalidades de privatização da educação, já apontadas por Gentili (1998).

Um outro dado construído em nossa pesquisa merece destaque quanto ao movimento instaurado na rede municipal de Goiânia no que se refere aos professores de educação infantil. A transferência das instituições da Fumdec para a SME implicou na supressão das funções de agente de saúde e assistente social. Por outro lado, passou-se a contar com outros profissionais, como, por exemplo, pedagogos e professores de educação física. Esta modulação de novos professores elevou o patamar de formação dos professores que atuavam diretamente com crianças menores de seis anos. No entanto, em 2003, esse quadro sofreu um retrocesso, impondo-se o critério de modular nos Cmeis apenas 50\% dos professores com formação em nível superior. As demais vagas de docentes passaram a ser preenchidas por profissionais com formação em magistério nível médio, na sua maioria contratados em regime temporário, o que, segundo nossas análises, gerou rotatividade de professores na rede e dificultou o trabalho pedagógico nas instituições e a mobilização política daqueles profissionais. Essa complexa movimentação trouxe, sem dúvida, reflexos na estruturação do campo educativo das instituições, indo contra as indicações de busca pela qualidade da educação infantil propaladas ao longo dos últimos trinta anos, sobretudo.

\section{A EdUCAÇÃo INFANTIL NÃO É PROBLEMA, É SOLUÇÃO}

A pesquisa sobre as políticas públicas para a educação infantil em Goiás tem indicado que, no que concerne às discussões políticas em torno da temática, encontramo-nos diante de um paradoxo: a educação infantil é vista como forma de efetivação de uma política voltada para o desenvolvimento político-social, mas, ao mesmo tempo, é classificada como problema. A reestruturação produtiva, o fortalecimento do neoliberalismo e a globalização/internacionalização da economia engendram transformações, entre as quais destacamos as tendências internacionais em ressignificar a infância e seu atendimento institucional, delimitando, no bojo de uma luta de forças, novas funções sociais das instituições educativas de crianças menores de sete anos. No contramovimento, de- 
vemos destacar a importância da constituição de posições progressistas e comprometidas do campo acadêmico-científico, abrangendo pesquisas sobre infância, movimentos pelos direitos das crianças, além de posições e lutas para interferir em mudanças efetivas na legislação educacional brasileira, tendo-se como pressuposto essencial que a educação infantil é, antes de tudo, direito da criança, da família e dever do Estado.

Desse modo, considera-se que, diante das inúmeras investidas pela privatização desse direito e, ainda, por causa da atitude dúbia em relação à educação infantil quanto aos recursos a ela destinados e à qualificação de seus profissionais, é preciso discutir e incentivar a ação autônoma de conselhos estaduais, municipais e de outros fóruns, a fim de defenderem de modo sistemático e efetivo a qualidade da educação infantil.

O que estamos resgatando aqui não é novo, porém ainda é válido apontar estes fatos quando se pretende examinar a forma estratificada como se vê a criança hoje. A criança continua a ser tratada como um "problema", não existindo clareza quanto à dialeticidade dos vários aspectos do seu aprendizado e desenvolvimento e sobre a importância da sua educação como parte de um projeto transformador da realidade desigual brasileira. Por esta razão, apesar de muitas discussões importantes e frutíferas sobre a educação infantil, sobretudo nas décadas de 1980 e 1990, que foram fundamentais no resgate dos direitos humanos referentes à infância, esta é concebida de modo compartimentado, apresentando-se como uma questão ora da àrea de saúde, ora da própria família ou da comunidade, ora do campo da educação.

É por essa razão, entre outras tantas, que várias secretarias estaduais e municipais de educação encontram-se ainda perplexas diante do desafio imposto a elas pela LDB/96 e pelo Plano Nacional de Educação. A educação infantil sempre foi de todos e nunca foi de ninguém, porque nunca houve uma preocupação mais sistemática com a continuidade de uma política de melhorias para a infância pobre no Brasil. Nenhum órgão público sente-se plenamente preparado hoje para criar propostas efetivas e suficientes de operacionalização da educação infantil, apesar de ela ter sido proposta oficialmente há quase cem anos. Afasta-se, nesse caso, do diálogo transformador das condições objetivas da realidade da infância pobre brasileira, servindo muitos programas assistenciais apenas para mascarar relações histórico-sociais e culturais contraditórias, de opressão e de oposição, travadas, inclusive, no esteio das políticas públicas para a infância. 
A educação infantil deve ser considerada um dos fins do projeto global das secretarias de educação, não sendo, portanto, um mero meio de alcançar sucesso em seus outros projetos. Daí ser ela, portanto, uma necessidade prioritária, devendo-se inseri-la simultaneamente em uma política de educação, de saúde e de bem-estar social. Isso porque a situação da infância, relacionada à dignidade, à cidadania e aos direitos humanos, não pode ser encarada como um "problema" da família ou da própria criança. A educação infantil deve ser pensada por todos os que desejam modificar o quadro de pobreza, indigência e miséria, de grandes concentrações de renda e de desigualdade social.

Assim, uma sociedade que se pretenda democrática e justa precisa respeitar a dignidade de todos os segmentos socioculturais, sem excluí-los econômica e socialmente dos mais variados benefícios, incluindo aqui as crianças e aqueles que as educam nas mais diferentes instituições. Nesse sentido, tal sociedade deve garantir aos professores e à criança que pretende constituir/transformar em cidadã - de direitos econômicos e políticos - com uma boa qualidade de vida.

\section{ABSTRACT}

This article presents a set of theoretical and methodological reflections on children's education in Goiás, and focuses on a set of significant information and data from the State and from the municipality of Goiânia, in particular. The data, drawn up from a dialectic perspective (Marx, 1983) herein presented, are based on studies and analyses undertaken over the last seven years. Different studies have been milestones along the path of the Group for Study and Research into Childhood and its Education, of the FE/UFG within the Research Project "Public Policies and Children's Education in Goiás: history, concepts, projects and practice". The results of the analyses and reflections allow for a discussion of the specific field of Children's Education and related policies within the State and also at national and international levels, leading to various contradictions. It can be seen that productive restructuring, growth of neo-liberalism and policies for the decentralization of resources and the centralization of power within the State create a paradox. Children's Education is seen as a means of promoting policies for political and social development, but at the same time, is classified as a problem. There is a growing movement towards the privatization and philanthropism of what is public in the case of Children's Education.

Keywords: Children's education. Neo-liberalism. Public policies. 


\section{NOTA}

1. O principal desses convênios foi firmado com a Associação das Creches Filantrópicas do Estado de Goiás (Aceg), disponibilizando vinte e oito professoras da SME para atuação nas instituições associadas.

\section{REFERÊNCIAS}

AGUIAR, A. R. de. Processos de constituição de conhecimentos pela criança através da linguagem. 2004. Dissertação. (Mestrado em Educação) - Faculdade de Educação da UFG, Goiânia.

ALVES, N. N. L. Elementos mediadores e significativos da docência em educação infantil da rede municipal de ensino de Goiânia. 2002. Dissertação. (Mestrado em Educação) - Faculdade de Educação da UFG, Goiânia.

ARANTES, M. M. Educação física na educação infantil: concepções e práticas de professores. 2003. Dissertação (Mestrado em Educação) - Universidade Estadual de Campinas.

BARBOSA, I. G. A creche: história e pressupostos de sua organização. Goiânia, 1999. (Impresso/prelo).

. Educação infantil: espontaneísmo versus escolarização. Goiânia: UFG, 2001. (Impresso).

; NOGUEIRA, M. A. A. Lei de Diretrizes e Bases do Estado de Goiás: avanços e limites no debate em torno da educação infantil. In: TOSCHI, M. S.; FALEIRO, M. de O. (Orgs.). A LDB do Estado de Goiás - Lei n. 26/98: análises e perspectivas. Goiânia: Alternativa, 2001.

BARBOSA, I; ALVES, N.; MARTINS, T. Políticas públicas para a educação infantil em Goiânia: a luta por um projeto político-social. Caxambu: Anped, 2005.

BRASIL. Congresso Nacional. Lei n. 9.394, de 20 de dezembro de 1996. Estabelece as Diretrizes e bases da Educação Nacional. Brasília, 1996. (Impresso).

CAMPOS, M. M. Pré-escola: entre a educação e o assistencialismo. Caderno de Pesquisa. São Paulo, (53): 21-24, maio, (1985).

GENTILI, P. A falsificação do consenso: simulacro e imposição na reforma educacional do neoliberalismo. 3. ed. Petrópolis, RJ: Vozes, 1998.

GOIÂNIA: CME. Resolução n. 014, de 23 de agosto de 1999.

. Resolução n. 088, de 20 de agosto de 2003. 
$1 / 2001$.

Diretrizes norteadoras para o currículo da educação infantil $n$.

. Resolução n. 108, de 30 de junho de 2004. Dispõe sobre o regimento dos Centros Municipais de Educação Infantil e dá outras providencias.

GOIÁS. Lei de Diretrizes e Bases do Sistema Educativo de Goiás, Lei Complementar n. 26, de 28 de dezembro de 1998.

LIMA, L. L. O. Políticas públicas educacionais para a educação infantil em Jatai: da proposição à materialização. 2005. Dissertação. (Mestrado em Educação) - Faculdade de Educação da UFG, Goiânia.

MARTINS, T. A. T.; BARBOSA, I. G. Trabalho docente: um olhar sob a teoria histórico-cultural. Goiânia, 2004. (Impresso).

MARX, K. O capital. Contribuição à crítica da economia política. São Paulo: Victor Civita. 1983.

MORAES, A. L. F. A avaliação na educação infantil: concepções e práticas dos professores dos Centros Municipais de Educação Infantil de Goiânia. 2004. Dissertação. (Mestrado em Educação) - Faculdade de Educação da UFG, Goiânia.

ROSEMBERG, F. Creche. São Paulo: Cortez, 1989.

. Organizações multilaterais, estado e políticas de educação infantil. Cadernos de Pesquisa. São Paulo, n. 115, p. 25-63, mar. 2002.

SOARES, E. P. Políticas públicas e educação infantil no estado do Tocantins: história e concepções norteadoras. 2005. Dissertação. (Mestrado em Educação) - Faculdade de Educação da UFG, Goiânia.

TOMMASI, L. de; WARDE, M. J.; HADDAD, S. O Banco Mundial e as politicas educacionais. São Paulo: Cortez, 2000.

VIEIRA, T. D. A Unesco e as políticas para a educação da infância: concepções e implicações nas políticas de educação infantil no município de Goiânia. 2004. Dissertação. (Mestrado em Educação) - Faculdade de Educação da UFG, Goiânia. 